\title{
STRUCTURE MATERIALS IN FUSION REACTORS: ISSUES RELATED TO TRITIUM, RADIOACTIVITY AND RADIATION-INDUCED EFFECTS
}

\author{
M. Rubel \\ Royal Institute of Technology (KTH), Dept. of Fusion Plasma Physics, Teknikringen 31, 10044 Stockholm, Sweden
}

\section{ABSTRACT}

A concise overview is given on materials applied in fusion technology. The influence of plasma operation on the behaviour of reactor components and diagnostic systems is discussed with emphasis on effects caused by fast particles reaching the reactor wall. Issues related to primary and induced radioactivity are reviewed: tritium inventory and transmutation. Tritium breeding in the reactor blanket, separation of hydrogen isotopes and safety aspects in handling radioactively contaminated components are also included.

\section{INTRODUCTION}

The ultimate goal of fusion research is to construct and operate an energy generating system. In a controlled fusion reactor the temperature gradients between the plasma and the surrounding wall will probably be the greatest in the Universe and the operation will be associated with intense nuclear radiation. Therefore, the technology for next-step devices presents challenges not encountered in present-day machines. This includes development and construction of components capable of reliable performance in highly radioactive environment.

The assessment of radioactivity level and lifetime of materials and components (multi-material structures) are the driving forces in studies of plasma-material interactions in controlled fusion devices [1,2]. They are essential for economy and safety of a reactor-class machine operated with a 50:50 mixture of deuterium and tritium. Secondly, radioactivity-related effects and power handling by plasma-facing components (PFC) are universal for all confinement schemes, either magnetic or inertial, realised for energy generating systems. A broad overview of power handling by the reactor first wall has been presented by Loarte [3] and Linke [4]. This paper deals with radioactivity aspects of the fusion process and its influence on reactor structure and plasma-facing materials and components. The paper is organised in such a way, that first basic requirements for plasma facing and reactor materials are presented. This is followed by a description of radioactivity sources in a fusion reactor. Afterwards tritium inventory, tritium breeding and radiation effects are discussed. The work is concluded with remarks on safety issues associated with handling components in radioactive environment. Finally, crucial topics to be tackled in future research of fusion reactor materials (FRM) are addressed.

\section{REACTOR STRUCTURE AND MATERIALS}

The next-step fusion machine is the International Thermonuclear Experimental Reactor (ITER) being under construction in Cadarache, France. The objectives of ITER science and technology programme include: (a) extended burn time; (b) achievement of a self-sustained thermonuclear burn; (c) safe operation of a reactor-like device; (d) testing of components under reactor-like conditions and (e) testing of tritium breeding blanket modules [5,6]. These are essential steps towards construction of power-generating systems in the future In brief, a reactor will be composed of a support structure, a cryostat with super-conducting magnets, a vacuum vessel and the first wall being an integrated blanket. The blanket includes structural materials, a neutron absorber and high-heat flux components, i.e. plasma-facing armour and heat sink.

Energy leaves plasma in the form of electromagnetic radiation and kinetic energy of particles. Plasmasurrounding wall is irradiated by ions, charge-exchange neutrals, electrons, neutrons and photons originating from nuclear $(\gamma)$ and electronic processes (X, UV). All of them modify material properties, from the very surface to the bulk. Therefore, blanket materials must be compatible with ultra-high vacuum, cryogenics (cryopumps), magneto-hydro dynamics, neutron irradiation and handling of high heat loads. As a consequence, there are stringent requirements regarding properties of plasma-facing materials (PFM): high thermal conductivity, good thermo-mechanical properties and resilience to thermal shocks, low activation by neutrons and resistance to radiation damage, low accumulation of hydrogen isotopes accompanied by low chemical affinity to hydrogen in order to avoid chemical erosion leading to the formation of volatile compounds. High affinity to oxygen towards formation of stable and non-volatile oxides is also important for gettering oxygen impurity species in a reactor. Properties of no single element, compound or alloy can satisfy all points from that list. Only a few candidate materials for the plasma-facing components are seriously considered: carbon fibre composites (CFC), beryllium and tungsten. Behaviour of these elements under plasma conditions, i.e. particle bombardment and high heat flux deposition, is very different [1-4]. Therefore, their planned distribution on the ITER wall is not accidental: beryllium on the main chamber wall; tungsten on the divertor dome and upper vertical target and CFC on the lower vertical target where the greatest power is deposited. A detailed distribution of $\mathrm{W}$ and 
CFC in the divertor has been discussed by Samm [7]. An option of a full tungsten divertor (without CFC) is currently considered [8]. The operation with such set of wall materials (Be, $\mathrm{W}$ and $\mathrm{CFC}$ or $\mathrm{Be}$ and $\mathrm{W}$ ) requires a large-scale test. In year 2004 it was decided to restructure wall components in the JET tokamak in order to operate the machine with a metal wall: ITER-Like Wall (ILW) Project with components of the main chamber wall made of beryllium and plasma-facing material in the divertor made of tungsten: bulk metal and W-coated CFC. The operation of JET with the carbon wall was finished in October 2009. The installation of the metal wall was completed in May 2011. Soon later plasma operation was successfully started. Photographs in Fig. 1 show in-vessel components and distribution of wall materials (a) and a section of the bulk tungsten divertor (b). Scientific objectives of the ILW project and challenges in the design and construction of components have been presented by Matthews [9,10] and Mertens [11], while plasma-wall interactions in a full metal machine have been reviewed by Matthews in [12].

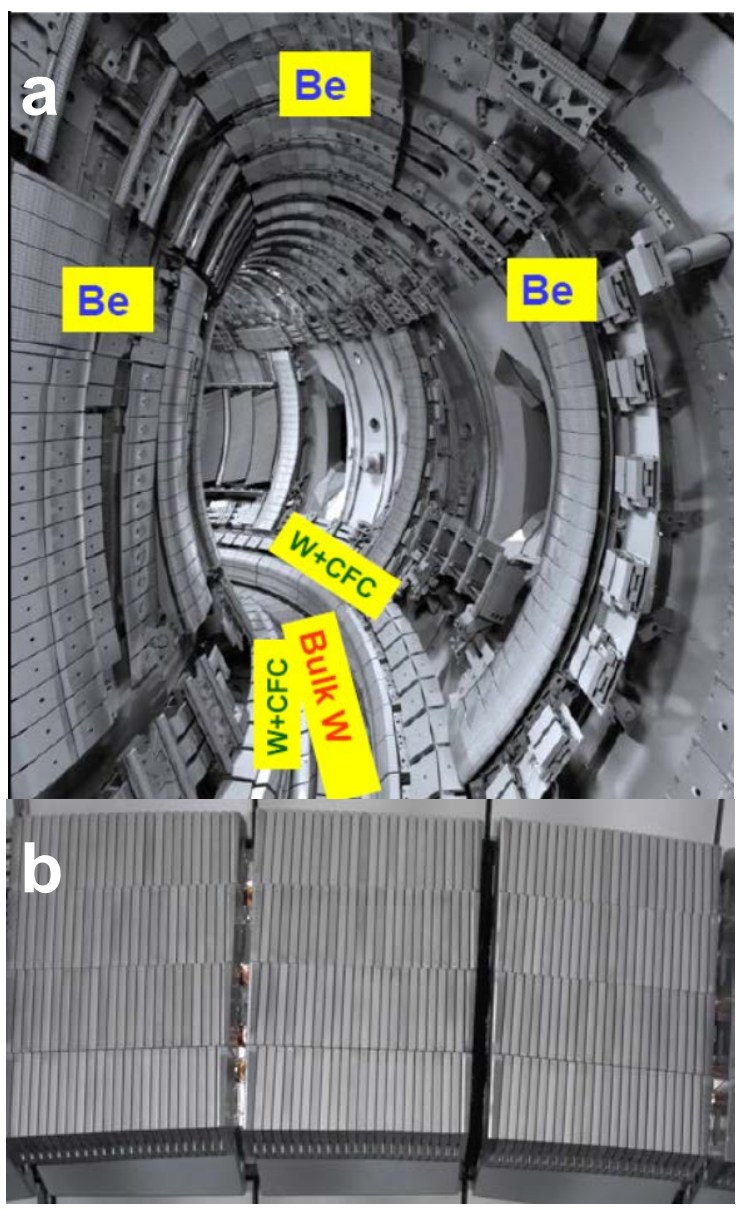

Figure 1: Toroidal view inside the JET vessel with the ITER-Like Wall (a) and a toroidal section of the tungsten load bearing plate in the divertor.

The list of candidate structural materials for the blanket comprises mainly steel (e.g. 316L), Eurofer alloy, vanadium-titanium alloys (V-Ti, V-Ti-Si, V-Ti$\mathrm{Cr})$ and silicon carbide composites [13]. Major requirements emphasise mechanical strength and low activation by neutrons. Low activation and increased resistance to radiation damage are also crucial for ceramic insulators and components of in-vessel diagnostic such as optical fibres, cables, mirrors and windows $[14,15]$.

The intention of this paper is to highlight the field of FRM and physics underlying their behaviour in radioactive environment, but not to give an extensive account on all ever-considered candidate materials and all kinds of radiation-induced effects. Only the most important processes affecting material properties will be discussed in more detail in Chapter V.

\section{SOURCES OF RADIOACTIVITY}

All primary and induced radioactivity in controlled fusion devices is associated with the substrates and products of the fusion process: tritium in the $\mathrm{D}-\mathrm{T}$ fuel and a consequent production of high energy neutrons:

$$
\begin{aligned}
& \mathrm{D}+\mathrm{T} \rightarrow \alpha(3.5 \mathrm{MeV})+\mathrm{n}(14.1 \mathrm{MeV}) \\
& \mathrm{D}+\mathrm{D} \rightarrow \mathrm{T}(1.01 \mathrm{MeV})+\mathrm{H}(3.03 \mathrm{MeV}) \\
& \mathrm{D}+\mathrm{D} \rightarrow{ }^{3} \mathrm{He}(0.82 \mathrm{MeV})+\mathrm{n}(2.45 \mathrm{MeV})
\end{aligned}
$$

The branching ratio of reactions (2) and (3) is around one. Tritium (symbol: $\mathrm{T}$ or ${ }^{3} \mathrm{H}$ ) is a low-energy $\beta^{-}$ emitter:

$$
{ }^{3} \mathrm{H}\left(\beta^{-}\right) \rightarrow{ }^{3} \mathrm{He}\left(18.59 \mathrm{keV}, \quad t_{1 / 2}=12.32 \text { years }\right)
$$

Resulting radioactivity of $1 \mathrm{~g}$ of tritium equals to 9652 Ci $\left(3.571 \times 10^{14} \mathrm{~Bq}\right)$. Safety requirements limit the invessel inventory to the total of $700 \mathrm{~g} \mathrm{~T}$. If this level would be overcome, a clean-up of the vessel would become necessary in order to reduce the radioactivity. Processes leading to the accumulation of tritium and methods of tritium removal will be discussed in the next chapter. In-situ induced radioactivity attributed to nuclear transmutation by fast neutrons passing the plasma-facing and structural materials of the blanket will be presented in Chapter V.

\section{IMPACT OF EROSION \& RE-DEPOSITION ON FUEL INVENTORY AND DUST GENERATION}

The term "fuel inventory" denotes accumulation and long-term retention of fuel in all in-vessel components, either those facing the plasma directly or located in remote (shadowed) areas such as water cooled louvers in the divertor structure $[1,16,17]$ or other parts of pumping ducts. This applies to all hydrogen isotopes and has several detrimental effects on the reactor operation. There are several pathways leading to the accumulation of fuel in reactor components:

i. direct implantation in the PFC surface region,

ii. T production by neutron-induced transmutation,

iii. diffusion and migration into the bulk,

iv. co-deposition process. 
Neutron-assisted production of $\mathrm{T}$ will be treated in the next chapter. The process of in-depth fuel migration into CFC materials is still under investigation in order to assess its impact on the overall inventory [18-20]. At present, there is a consensus that the process of codeposition is decisive for the in-vessel fuel accumulation.

Co-deposition is defined as re-deposition of eroded and then transported material (i.e. plasma impurities) together with fuel species. Material eroded from one place of the reactor wall is re-deposited in another location, unless it is pumped-out [8,21]. The most serious consequence of co-deposition is the formation of mixed-material layers which may contain vast amounts of fuel. The process that has been studied most extensively in devices with carbon walls is directly related to the pronounced erosion (physical and chemical) of carbon by hydrogen plasma and the resultant formation of various hydrocarbon species. They are characterised by different sticking coefficients to solid surfaces [22]. Those of a high sticking co-efficient are easily deposited and form amorphous carbonaceous (a:C-H) films retaining from a few to about $50 \%$ atomic percent of hydrogen isotopes [16,23]. As measured in various tokamaks, the growth rate of such films is usually between 1.5 and $12 \mathrm{~nm} / \mathrm{s}$. When this number is scaled-up to a full year of plasma operation co-deposited layer of a thickness from $4.7 \mathrm{~cm}$ to $38 \mathrm{~cm}$ would be formed, respectively. This indicates the scale of the problem arising from the carbon erosion, its redeposition and fuel inventory. The retention of radioactive tritium causes the most severe problems because methods must still be developed to accomplish the efficient release of fuel and/or decomposition and removal of co-deposits in order to ensure safe and economical reactor operation. A range of concepts has been proposed and tested in laboratories [24-27] and also inside tokamaks [28-30].

Fig. 2 shows a limiter tile exposed to the tokamak plasma for a few operation hours. One can distinguish two regions: a shiny and smoothly looking erosion zone and a deposition zone covered with a peeling-off (flaking) deposit. Images in Fig. 3 and 4 show two basic micro-structures of co-deposited films: granular and stratified (laminar), respectively [31,32]. The layers shown here are 30-50 micrometers thick, but the formation of much thicker deposits $(1 \mathrm{~mm})$ has been also observed on the neutraliser plates of the belt pump limiter at TEXTOR [31]. Thick deposits are very brittle, easily disintegrate and thus fuel-rich dust is produced. The amount of dust in the reactor must be strictly controlled as it poses danger of ignition and steam reaction in case of accidental massive air or cooling water leak into the vacuum vessel. Dust generation mechanism, motion in plasma and morphology of particulates has been intensively studied [32-35]. In JET with full metal fuel accumulation has been reduced by a factor of 10 in comparison to that measured with carbon walls [12].

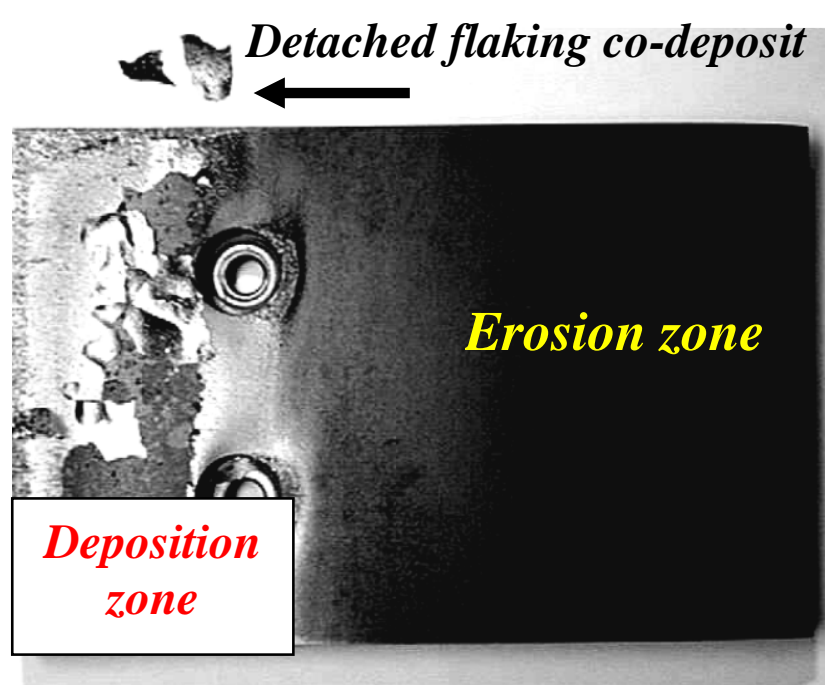

Figure 2: Limiter tile exposed for several hours to the plasma operation at the TEXTOR tokamak.

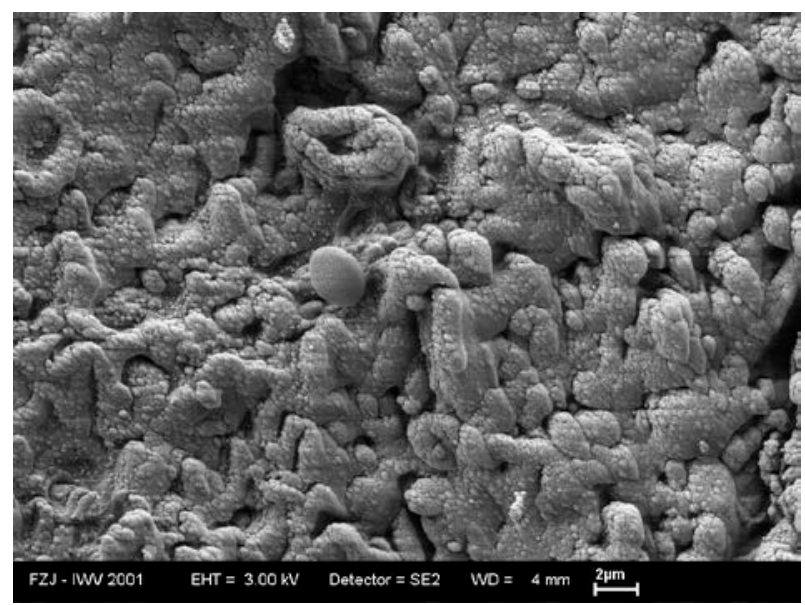

Figure 3: Granular structure of a co-deposit on the scoop of the toroidal belt pump limiter at TEXTOR.

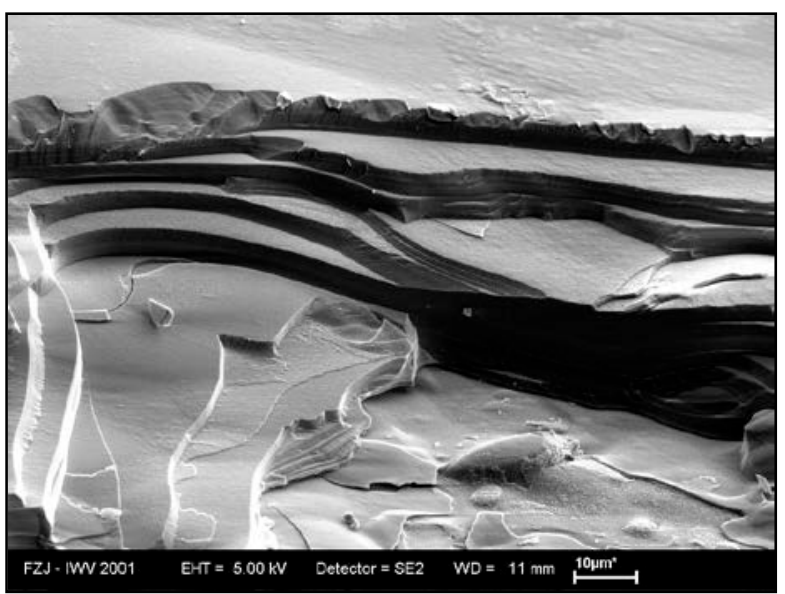

Figure 4: Stratified co-deposit on the limiter tile from TEXTOR. The tile is shown in Figure 2.

The estimated fuelling rate of the ITER plasma is around $54 \mathrm{~g}$ of $\mathrm{T}$ per $400 \mathrm{~s}$ pulse. From this amount approximately only $1 \mathrm{~g}$ will be burnt in the $\mathrm{D}-\mathrm{T}$ fusion, whereas the remaining majority must be pumped out and returned to the tritium plant (the plant is discussed in 
Chapter VII). However, the pumped-out fraction will depend on the long-term tritium retention in co-deposits. Predictions have been made for the cumulative tritium retention in co-deposited carbon films until the safety limit for in-vessel inventory (700 g) is reached and a clean-up must be performed [1]. The predictions have been based on the experience gathered after the full D-T operation in JET and on scenarios modelled by computer codes for erosion and re-deposition. One could conclude that the clean-up would be necessary after 30-40 (JET equivalent at full carbon wall) to 350-400 ITER pulses (inventory $2 \mathrm{~g} /$ pulse with carbon tiles only in the strike zone in the divertor). Whichever inventory scenario might take place in the reactor, frequent breaks in the operation must not happen because it would have a serious impact on the economy of operation. It would also severely hinder efficient realisation of the scientific and technical programme. Therefore, either carbon PFC should be eliminated and replaced by tungsten (see [8]) or/and efficient methods for tritium removal must be fully developed. Both approaches are complex but they are under intense experimental scrutiny. A comprehensive test of materials and their impact on fuel accumulation is one major goals of JET-ILW.

Several methods of $\mathrm{T}$ removal and vessel clean-up were tested at TFTR and JET following full D-T campaigns [24,28]: tokamak discharges in $D_{2}$ fuelled plasma, $\mathrm{H}$ and He glow discharge cleaning, venting with oxygen. Tokamak discharges and hydrogen glow aim at the $\mathrm{D}-\mathrm{T}$ and $\mathrm{H}-\mathrm{T}$ isotope exchange. Helium glow sputters away isotopes from the surface layer. Ventilation with air leads to the formation of tritiated water. While the $\mathrm{T}$ removal from the main chamber (PFC) could be deemed reasonable effective, the removal rate from remote areas, where the thickest tritiated co-deposits were formed, was poor. Peeled-off flakes were removed by vacuum cleaning. Several other methods for tritium and co-deposit removal have been proposed and tested under laboratory conditions. They are based on chemical decomposition ( $\mathrm{H}$ and He glow plasma with water vapour [25], $\mathrm{O}_{2}$-He glow [29]), pulsed irradiation [26,27] or mechanical treatment of surfaces with co-deposits [36]. Irradiation with a laser [27] or flash light [29] stimulates desorption of $\mathrm{H}$ isotopes and disintegration of co-deposits. However, the side effect of the deposit removal and disintegration is the formation of dust particulates. Another challenge is related to development of an efficient method to remove codeposits from gaps between tiles and grooves of castellation [37]. The issue is important because all plasma-facing components in ITER will be castellated and the number of narrow grooves will be over one million. Full scale in-situ tests are still to be done in a tokamak environment. Taking into account a variety of co-deposit structures and their location in the reactor, a combination of techniques must be applied. An overview of methods has been presented by Counsell [38]. Full metal wall can mitigate the retention. As mentioned above, the fuel inventory in JET-ILW has been vastly reduced [12].

\section{RADIATION-INDUCED EFFECTS}

Properties of reactor materials and components are modified by fast neutrons and ionising radiation: $\gamma, \mathrm{X}$ and UV. The neutron flux to the wall of ITER will be of the order of $5 \times 10^{17} \mathrm{~m}^{-2} \mathrm{~s}^{-1}$. Energy carried by $14 \mathrm{MeV}$ neutrons must be converted in the blanket into heat and tritium breeding. The blanket acts as a neutron absorber and T-breeder. Its additional important role is the protection of the vacuum vessel and super-conducting coils from neutron irradiation. Neutrons, on their way through the armour and structural components of the blanket, cause volumetric radiation damage and chemical modification leading to the change and deterioration of material properties. The major neutroninduced effects in solids are: structural damage (displacement damage) [39,40] and nuclear transmutation [41]. These are very closely inter-related processes and they affect all types of materials. Some specific effects are induced by fast photons in ceramic insulators.

The measure of damage to a crystalline matter caused by bombardment with energetic particles is expressed in terms of "displacement per atom” (dpa), i.e. the number of times each atom is dislodged by radiation from its place in the crystal. In other words, $1 \mathrm{dpa}$ is equivalent to displacing all atoms once from their lattice sites. The cross-section for processes of neutron displacement damage is generally in the range from 1 to 10 barns $\left(1 \mathrm{~b}=10^{-28} \mathrm{~m}^{2}\right)$. Damage depends on the fluence (total dose) and, in some cases, also on the neutron flux. For instance, in carbon, beryllium or ceramic materials 1 dpa is produced by a neutron dose of around $1 \times 10^{25} \mathrm{~m}^{-2}$. Volumetric damage leads to the formation of dislocations, interstitials, voids and vacancies in the crystal lattice. This results from the direct knock-on of atoms and/or ions from their sites. Knock-on atoms of sufficiently high energy may produce further displacements by cascades. Dislocation is defined as a line, plane or region in which there is a discontinuity in the regularity of the lattice. Voids and vacancies are the empty spaces formed by shifting the atoms from their original sites. In the end effect materials volume is changed due to swelling (metals, ceramics) or shrinkage (CFC). 1 dpa typically results in $1 \%$ volume change. This in turn, leads to the significant drop in thermal conductivity, even by $70 \%$ from the original value [42]. Swelling of a metal crystal changes drastically its mechanical properties causing hardening and resultant increased brittleness (embrittlement). The extent of the damage is reduced at elevated temperatures due to annealing. However, it is obvious that the temperature of materials and components cannot be increased indefinitely. Therefore, efforts in irradiation tests are focused on the definition of operation limits, i.e. dose and temperature.

The processes described above apply also to all insulating ceramics applied as important components of heating and current drive and diagnostic systems 
exposed directly to neutron fluxes: feed-through assemblies, magnetic pick-up coils, mineral insulated cables, bolometers, pressure gauges, thermocouples, other temperature sensors, optical fibres, laser diodes, detectors, windows, mirrors, etc $[15,43]$. For insulators the requirements are more stringent than for metallic materials because it is necessary to maintain not only their mechanical performance but also sensitive physical properties such as electrical insulation and optical transmission. These properties are influenced by neutrons and photons due to radiation-induced or radiation-enhanced:

i. conductivity (excitation of electrons into a conduction band),

ii. electrical degradation (increased electrical conductivity),

iii. absorption (light transmission loss),

iv. electromotive force (induced voltage between the centre and outer conductors of a mineral insulated cable),

v. radiation-enhanced diffusion (for instance increased tritium mobility in ceramic windows).

To ensure reliable performance of insulated devices further testing and development of radiation-hard materials must be carried out. The list of examined ceramic materials include $\mathrm{Al}, \mathrm{Mg}, \mathrm{Si}$, Be oxides, nitrides $\left(\mathrm{Si}_{3} \mathrm{~N}_{4}\right)$, natural and CVD-diamonds, mica and ferroelectrics.

The second fundamental radiation-induced effect is transmutation defined as the change in a nucleus structure leading to the formation of different isotope(s) or element(s) induced by bombarding the nucleus with particles or photons. In case of photons the process goes via the Compton effect. The efficiency of transmutation, as for all nuclear reactions, depends on the cross-section of a given nuclear process. Basically, neutron-induced transmutation can be divided into three categories dependent on the reaction products:

i. formation of gaseous species such as hydrogen isotopes and helium: (n,p), $(n, n p),(n, d),(n, t)(n, \alpha),(n, n \alpha)$,

ii. gamma radiation: $(n, \gamma),\left(n, n^{\prime} \gamma\right)$

iii. neutron breeding: $(n, 2 n),(n, 3 n)$.

One may easily notice that the first-group processes lead to the formation of hydrogen isotopes $(H, D, T)$ or helium. Gases accumulated in the crystal lattice form bubbles and blisters. Bubbles are formed not only in the surface layer but also in the bulk. This increases brittleness. When the pressure of the accumulated gas overcomes a certain limit, blisters explode leading to the exfoliation (example is shown in Fig. 5).

An important consequence of nuclear reactions is simultaneous formation of other (than $\mathrm{H}$ and $\mathrm{He}$ ) transmutation products modifying material properties. The problem associated with such impurities becomes particularly serious following high-dose irradiation. Secondly, some of those transmutation products are radioactive isotopes. Basic physics underlying the transmutation cannot be overcome and the only way to minimize its effects is to use low-activation materials, i.e. materials containing elements of low cross-section for transmutation or elements whose transmutation products are either non-radioactive or isotopes of short lifetime. It is clear that products and related radioactivity (i.e. energy spectrum and lifetime) strongly depend on the initial composition of the irradiated material. It also implies that not only major constituents must undergo low activation but also the quantity and quality of admixtures and impurities must be strictly controlled. For instance, while major constituents of a low activation vanadium alloys (V-3Ti-1Si) transmute to isotopes of short lifetime, the presence of nickel impurities transmuted to ${ }^{60} \mathrm{Co}$ leads to a long-term activation $\left(\mathrm{t}_{1 / 2}{ }^{60} \mathrm{Co}=5.27\right.$ years $)$. In conclusion, fabrication of low activation and high purity FRM is essential.

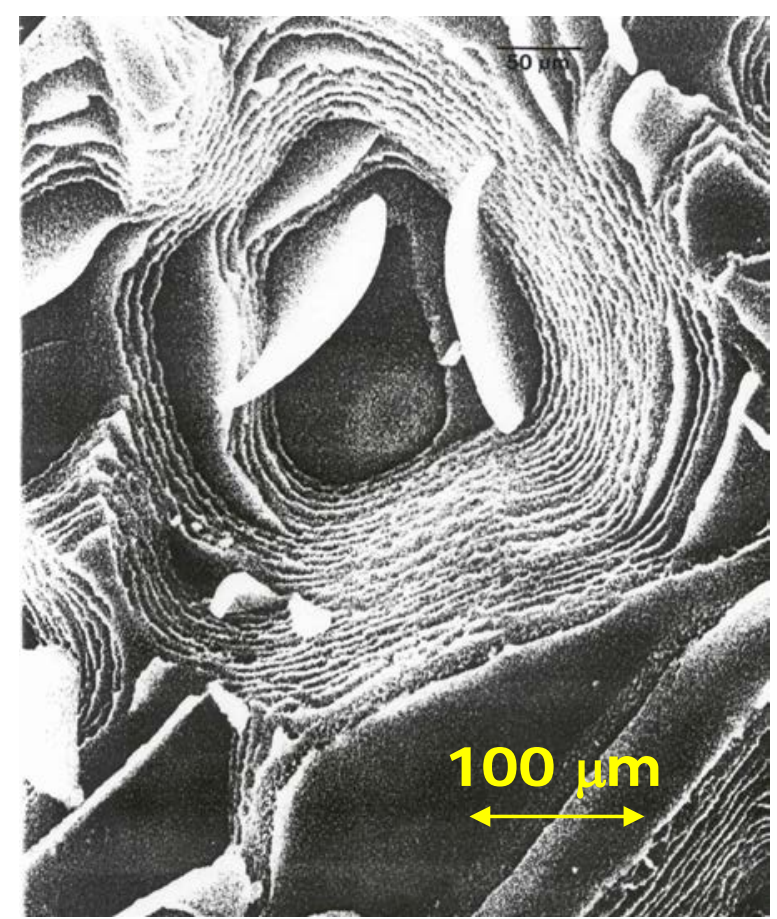

Figure 5: Exfoliation of metal following high dose irradiation.

\section{TRITIUM BREEDING IN THE BLANKET}

As already pointed out, the conversion of neutron energy to heat and T-breeding takes place in the absorber part of the blanket. The role of blanket is also to shield superconducting magnets (niobium tin $\mathrm{Nb}_{3} \mathrm{Sn}$ and/or niobium-titanium $\mathrm{Nb}-\mathrm{Ti}$ ) against neutrons and gamma radiation [44]. Three test tritium breeding blanket modules (TBM) are planned to be installed in ITER. The aim of TBM implementation in ITER is to test their performance and verify technology for DEMO, i.e. for a prototype of a power-generating fusion reactor. The modules are composed of structural (i.e. containment and coolant loop made of EUROFER) and functional materials (i.e. breeder). Two basic coolants have been 
considered: water and high-pressure helium [45]. Figure 6 shows a scheme of helium-cooled blanket being developed for DEMO.

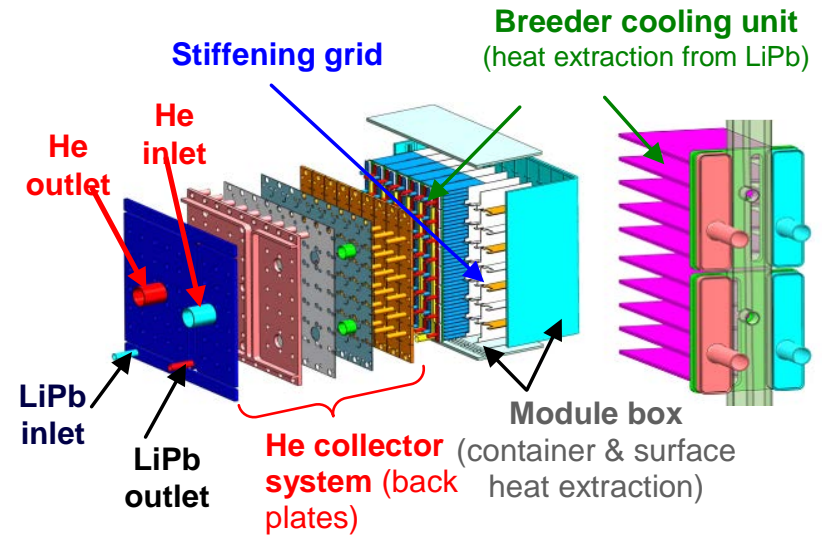

Figure 6: Schematic view of a helium-cooled blanket module to be operated with liquid lithium-lead developed for DEMO. Source: EFDA.

Lithium is an efficient breeder. Therefore, it is a constituent of all candidate materials considered for the absorber. Lithium has two stable isotopes ${ }^{6} \mathrm{Li}$ and ${ }^{7} \mathrm{Li}$ with natural abundance of $7.5 \%$ and $92.5 \%$, respectively:

${ }^{6} \mathrm{Li}+\mathrm{n} \rightarrow \alpha+\mathrm{T}+4.78 \mathrm{MeV} \quad\left(E_{t h}=2.47 \mathrm{MeV}\right)$

${ }^{7} \mathrm{Li}+\mathrm{n} \rightarrow \alpha+\mathrm{T}+\mathrm{n}$ ' $2.47 \mathrm{MeV}$

where $E_{\text {th }}$ denotes the threshold energy of the process. These reactions are essential for tritium production because that isotope must be produced on site. Several ceramics have been tested: $\mathrm{Li}_{2} \mathrm{ZrO}_{3}, \mathrm{Li}_{8} \mathrm{ZrO}_{6}, \mathrm{Li}_{2} \mathrm{TiO}_{3}$, $\mathrm{LiAlO}_{2}, \mathrm{Li}_{2} \mathrm{SiO}_{3}$ and $\mathrm{Li}_{4} \mathrm{SiO}_{4}{ }^{46}$. The other candidates are lithium oxide $\left(\mathrm{Li}_{2} \mathrm{O}\right)$, Li17-Pb liquid alloy (eutectic) and $2 \mathrm{LiF}-\mathrm{BeF}_{4}$ mixture called Flibe, $\mathrm{Li}_{2} \mathrm{BeF}_{4}$. To increase the amount of neutrons for $\mathrm{T}$ breeding, beryllium is added as a neutron multiplier:

${ }^{9} \mathrm{Be}+\mathrm{n} \rightarrow 2 \alpha+2 \mathrm{n}, \quad\left(E_{t h}=2.7 \mathrm{MeV}\right)$

However, other side reactions with low cross-sections also occur thus leading to the production of tritium and helium and, eventually, to accumulation of tritium in $\mathrm{He}$ bubbles in Be:

$$
\begin{aligned}
& { }^{9} \mathrm{Be}+\mathrm{n} \rightarrow \alpha+{ }^{6} \mathrm{He} \quad\left(E_{t h}=0.67 \mathrm{MeV}\right) \\
& { }^{6} \mathrm{He}\left(\beta^{-}\right) \rightarrow{ }^{6} \mathrm{Li} \quad\left(3.508 \mathrm{MeV}, t_{1 / 2}=0.807 \mathrm{~s}\right) \\
& { }^{9} \mathrm{Be}+\mathrm{n} \rightarrow{ }^{7} \mathrm{Li}+\mathrm{T}-10.40 \mathrm{MeV}\left(E_{t h}=11.6 \mathrm{MeV}\right)
\end{aligned}
$$

Then, ${ }^{6} \mathrm{Li}$ and ${ }^{7} \mathrm{Li}$ are transmuted to tritium in processes (5) and (6), respectively. Taking into account all these pathways of $\mathrm{T}$ generation from lithium, the overall fusion process reads:

$$
\mathrm{D}+\mathrm{Li} \rightarrow 2 \alpha+\text { Energy }
$$

showing that the energy production cycle is based on easily achievable reactants found in nature in inexhaustible supply: deuterium extracted from sea water $\left(\sim 33.3 \mathrm{~g} \mathrm{D} / \mathrm{m}^{3}\right)$ and lithium extracted from sea water or obtained from common minerals such as lepidolite, petalite, spodumene and amblygonite.

\section{TRITIUM PLANT}

Tritium breeded in the blanket and that pumped-out from the torus (non-used fuel and released from the wall by cleaning methods) must be handled in the tritium plant before it can be used for plasma fuelling. Tritiated species occur in the form of gas molecules $\left(I_{2}\right.$, where I denotes a mixture of hydrogen isotopes), hydrocarbons $\left(\mathrm{C}_{\mathrm{x}} \mathrm{I}_{\mathrm{y}}\right)$ and water $\left(\mathrm{I}_{2} \mathrm{O}\right)$. The separation methods comprise cryogenic distillation, condensation, electrolysis, diffusion via $\mathrm{Pd}$ membranes, catalytic processes: oxidation of $\mathrm{C}_{\mathrm{x}} \mathrm{I}_{\mathrm{y}}$, decomposition of $\mathrm{I}_{2} \mathrm{O}$ and $\mathrm{C}_{\mathrm{x}} \mathrm{I}_{\mathrm{y}}$ and vapour stage exchange:

$$
\begin{array}{ll}
\mathrm{CO}+\mathrm{I}_{2} \mathrm{O} \leftarrow \rightarrow \mathrm{CO}_{2}+\mathrm{I}_{2} & \text { [water gas shift] } \\
\mathrm{CI}_{4}+\mathrm{I}_{2} \mathrm{O} \leftarrow \rightarrow \mathrm{CO}+3 \mathrm{I}_{2} & \text { [steam reforming] } \\
\mathrm{CI}_{4} \leftarrow \rightarrow \mathrm{C}+2 \mathrm{I}_{2} & \text { [methane cracking] }
\end{array}
$$

Fig. 7 shows a schematic flow diagram in an isotope separation facility [47]. This example is based on the Tritium Separation Test Assembly, TSTA, operated until 1997 in Los Alamos NL, New Mexico, USA. Details of the ITER fuel cycle have been recently presented by Mardoch [48].

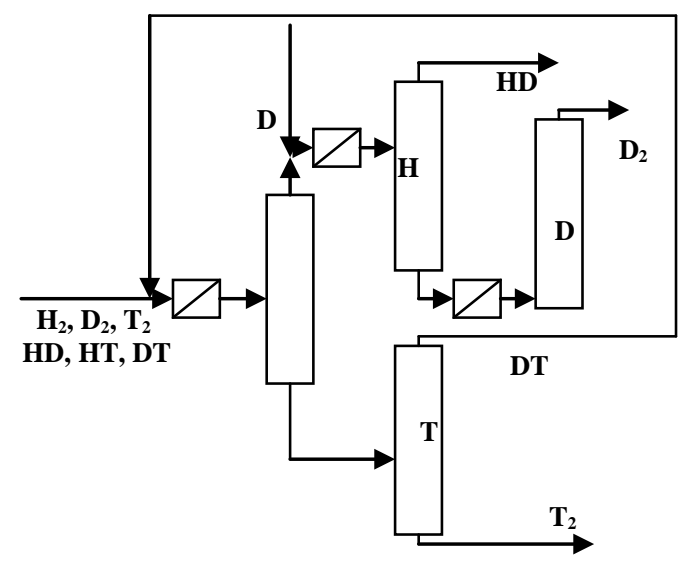

Figure 7: A schematic flow diagram of tritiated gases in an isotope separation station (ISS).

All tritium for introduction to the torus (freshly supplied to the reactor site and that leaving the ISS) must be stored in uranium or Co-Zr beds at low temperature. This is to ensure precise dosing and to avoid uncontrolled release of the radioactive gas. Also deuterium for the gas introduction system is stored in Ubeds. The discharge of pure gases from the beds is realised at elevated temperature of about $450{ }^{\circ} \mathrm{C}$ [28].

\section{SAFETY ASPECTS AND HANDLING OF REACTOR COMPONENTS}

Already the D-D phase of the ITER operation will activate components to the level unacceptable for manned intervention in the reactor vessel. Radioactivity will be significantly increased in the $\mathrm{D}-\mathrm{T}$ phase. Additionally, the use of beryllium (health hazard) on the entire wall of the main chamber imposes strict 
precautions for in-vessel operation during shut-down periods. Therefore, like in other branches of nuclear industry, the design and construction of all in-vessel components of a fusion reactor is fully compatible with remote handling by robotic arms. The major role of these programmed (trained) devices is in installation, exchange and repair of PFC, blanket, divertor modules and in-vessel diagnostics. Fig. 8 shows a robotic arm used in the JET tokamak. The technology was developed for handling components following the full D-T campaign $[28,49]$. All replacements of the JET divertor structure and installation of diagnostic tools are performed by these means. Remote handling technology at JET has been further developed to meet requirements in installation of beryllium and tungsten components for the ILW project. This has comprised a design and construction of a new robot capable of handling components of up to $100 \mathrm{~kg}[9,10]$.

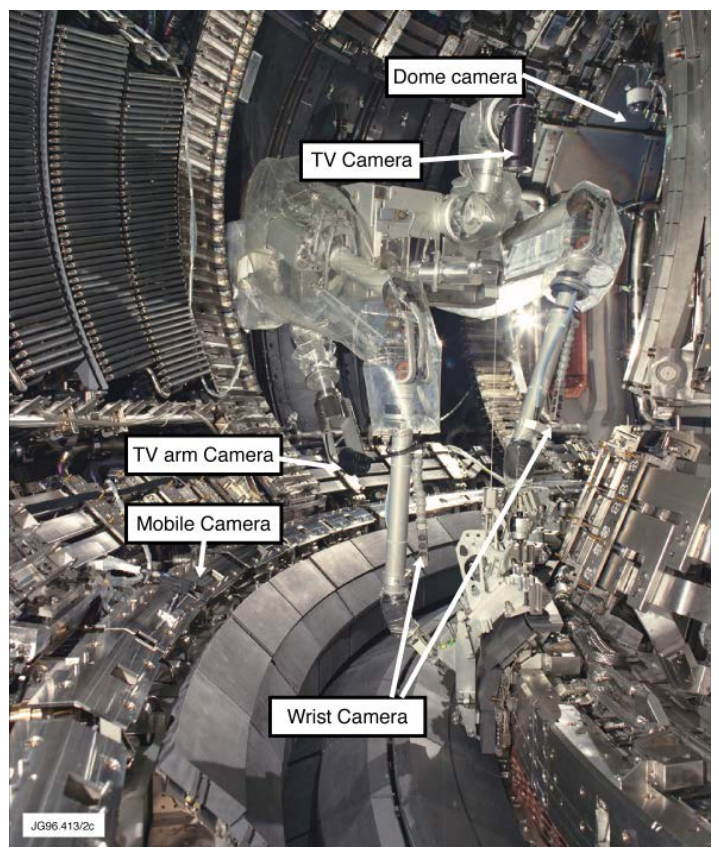

Figure 8: A remotely controlled robotic arm at JET: restructuring of the divertor configuration (1998).

\section{FUTURE STUDIES OF FUSION REACTOR MATERIALS}

The list of most important issues to be tackled on the way towards the reactor construction includes:

i) further development of low-activation and radiation-hard materials and components of high purity,

ii) development of efficient techniques for tritium removal or elimination of carbon as material for PFC in order to reduce inventory related to the co-deposition,

iii) testing of materials and components under highflux irradiation with $14 \mathrm{MeV}$ neutrons.

The last point requires a construction of an efficient test facility capable of simulating the neutron energy spectrum of a D-T fusion reactor. Sufficient intensity of the n-flux and the irradiation volume of at least $500 \mathrm{~cm}^{3}$ are indispensable for testing samples of candidate materials up to a full lifetime of anticipated use in a reactor (e.g. DEMO), i.e. over 80 dpa. A conceptual design of the facility has been completed. Engineering validation and engineering design activity (EVEDA) phase will soon begin and it should be followed by decisions regarding the site for the facility and work schedule. The project is called IFMIF: International Fusion Material Irradiation Facility [50]. The facility shown schematically in Fig. 9 is an intense neutron source based on an accelerator-driven generation of neutrons by deuterium-lithium reactions: ${ }^{7} \mathrm{Li}(\mathrm{d}, 2 \mathrm{n}){ }^{7} \mathrm{Be}$, ${ }^{6} \mathrm{Li}(\mathrm{d}, \mathrm{n})^{7} \mathrm{Be}$. Deuterons in the range of $30-40 \mathrm{MeV}$ are to be produced by means of two continuous-wave linear accelerators. Interaction of deuterons in a flowing lithium target would lead to production of neutrons with the energy spectrum peaking at around $14 \mathrm{MeV}$. The neutron generation rate of some $10^{17} \mathrm{n} \mathrm{s}^{-1}$ would result in a flux of some $10^{19} \mathrm{~m}^{-2} \mathrm{~s}^{-1}$ at the rear side of the target. Therefore, displacement damage and transmutation products $(\mathrm{He})$ in the irradiated material would match the neutron-induced effects anticipated in the fusion reactor environment. Fig. 10 shows a scheme of the IFMIF test assembly and target chambers.

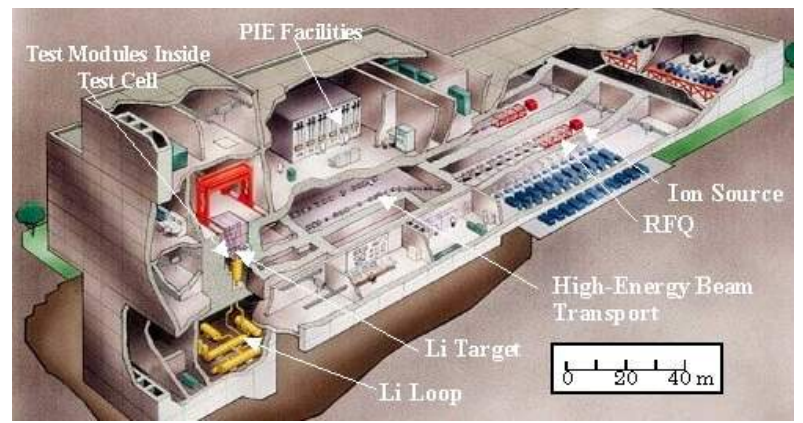

Figure 9: A schematic view of IFMIF.

(Source:http://insdell.tokai.jaeri.go.jp/IFMIFHOME/ifmi f_home_e.html)

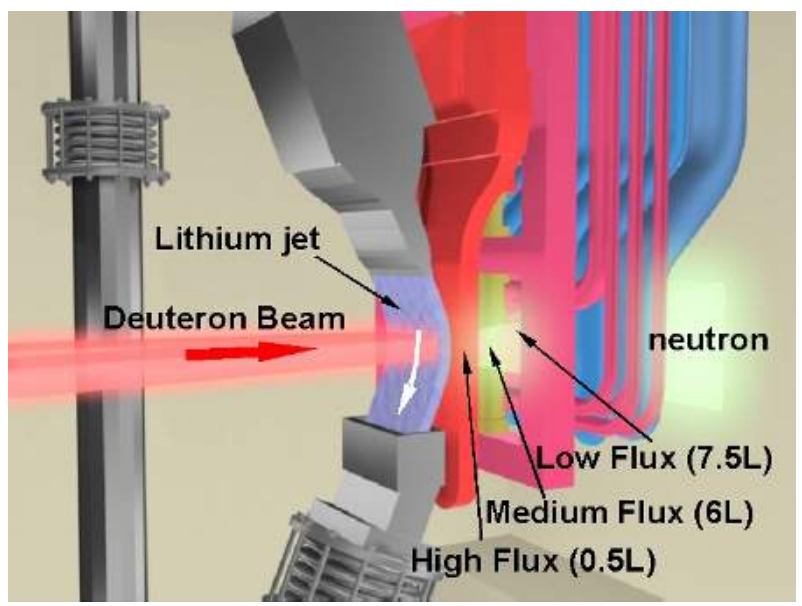

Figure 10: IFMIF: liquid lithium target and characteristics of target chambers.

(Source:http://insdell.tokai.jaeri.go.jp/IFMIFHOME/ifmi f_home_e.html) 


\section{CONCLUDING REMARKS}

The above mentioned aspects of material science are necessary and important to accomplish the ultimate goal of fusion research, i.e. the construction of a power generating system. Development and intense testing of materials and components, will play a crucial role in and for the operation of ITER and DEMO machines. Having in mind scientific and technical challenges associated with the project, all efforts are to be made to ensure the best possible material selection for a reactor-class machine. Fusion, if realised under terrestrial conditions, offers inexhaustible energy supply free of $\mathrm{CO}_{2}$ emission. However, a reactor is a nuclear device and radioactive aspects of fusion will undergo intense public scrutiny. For that reason, proper testing and validation of material and component performance is essential. Based on the best of our present knowledge [51,52] we have to use and to develop tools, methods and materials best fitted for the steady-steady reactor operation. International cooperation established around ITER is an important step on the way towards commercial fusion.

The lecture has addressed not only problems and future challenges but also achievements in technology of FRM. With the present-day experience and background from many fields of science and technology we know "what" and "why" may happen with materials in a hostile fusion environment. This, in turn, allows definition of actions "how" to deal with problems and reach solutions. It certainly still requires substantial funding but also a lot of invention. In that sense, fusionrelated material research is an attractive and long-term field for a generation of young scientists and nuclear engineers.

\section{REFERENCES}

1. G. Federici et al., "Plasma-Material Interactions in Current Tokamaks and their Implications for Next Step Fusion Reactors”, Nucl. Fusion, 41, 1967 (2001).

2. W. O. Hofer and J. Roth (Eds), Physical Processes of the Interaction of Fusion Plasmas with Solids, Academic Press, New York (1996).

3. A. Loarte, "Implications of the Use of CarbonBased Plasma Facing Components in Next Step Fusion Devices”, Phys. Scr., T111, 13 (2004).

4. J. Linke, "Plasma Facing Materials and Components Future Fusion Devices: Development, Characterisation and Performance under Fusion Specific Loading Conditions”, Phys. Scr., T123, 45 (2006) and These proceedings.

5. Progress in the ITER Physics Basis, Nucl. Fusion, 47 (2007) (also: www.iter.org).

6. R.A. Pitts et al., "Status and Physics Basis of the ITER Divertor”, Phys. Scr. T138, 014001 (2010).

7. U. Samm, "Plasma - Wall Interaction", These proceedings.
8. R.A. Pitts, “A Full Tungsten Divertor for ITER: Physics Issues and Design Status”, J. Nucl. Mater., 438, S48 (2013).

9. G. F. Matthews et al. "Overview of the ITER-Like Wall Project”, Phys. Scr., T128, 137 (2007).

10. G.F. Matthews et al., "The JET ITER-Like Wall Status and Experimental programme”, Phys. Scr., T145, 014001 (2011).

11. Ph. Mertens at al., "Detailed Design of a Solid Tungsten Divertor at JET”, Phys. Scr., T145, 014002 (2011).

12. G.F. Matthews, "Plasma Operation with an All Metal First Wall: Comparison of an ITER-Like Wall and a Carbon Wall in JET”, J. Nucl. Mater., 438, S2 (2013).

13. E. E. Bloom, “The Challenge of Developing Structural Materials for Fusion Power Systems”, $J$. Nucl. Mater., 258-263, 7 (1998).

14. T. Yano et al, "Physical Property Change of Neutron Irradiated CVD-diamond, Silicon and Silicon Carbide”, J. Nucl. Mater., 307-311, 1102 (2002).

15. M. Decréton, T. Shikama and E. Hodgson, "Performance of Functional Materials and Components in a Fusion Reactor: the Issue of Radiation Effects in Ceramics and Glass Materials for Diagnostics”, J. Nucl. Mater., 329-333, 125 (2004).

16. J. P. Coad et al., "The Amount and Distribution of Deuterium Retained in the JET Divertor after the C and Be Phases”, J. Nucl. Mater,. 241-243, 408 (1997).

17. M. Rubel et al., "Beryllium and Carbon Films in JET following D-T Operation”, J. Nucl. Mater., 313-316, 323 (2003).

18. B. Emmoth, M. Rubel and E. Franconi, "Deep Penetration of Deuterium in Carbon-Based Substrates”, Nucl. Fusion, 30, 1140 (1990).

19. V. K. Alimov and J. Roth, "Hydrogen isotope retention in plasma-facing materials: review of recent experimental results", Phys. Scr., T128, 6 (2007).

20. A. Kreter et al., "Deuterium Retention in Different Carbon Materials Exposed at TEXTOR“, J. Physics Conf. Series, 100, 062024 (2008).

21. V. Philipps et al., "Erosion and Re-deposition of Wall Material in Controlled Fusion Devices”, Vacuum, 67, 399 (2002).

22. A. von Keudell et al., "Surface Loss Probabilities of Hydrocarbon Radicals on Amorphous Hydrogenated Carbon Film Surfaces”, Nucl. Fusion, 39, 1451 (1999).

23. M. Rubel et al., "Analysis and Oxidation of Thick Deposits on TEXTOR Plasma Facing Components”, J. Nucl. Mater., 266-269, 1185 (1999). 
24. C.H. Skinner et al., "Plasma Wall Interaction and Tritium Retention in TFTR”, J. Nucl. Mater., 241243, 214 (1997).

25. B. Landkammer et al.,’Erosion of Thin Hydrogenated Carbon Films in Oxygen, Oxygen/Hydrogen and Water Plasmas”, J. Nucl. Mater. 264, 148 (1999).

26. C. H. Skinner et al., ”Thermal Response of Tritiated Co-deposits from JET and TFTR to Transient Heat Pulses”, Phys. Scr., T103, 34 (2003).

27. D. Ivanova et al., "Laser-based and Thermal Methods for Fuel Removal and Cleaning of PlasmaFacing Components”, J. Nucl. Mater., 415, S801 (2011).

28. D. Stork (Ed.), Technical Aspects of DeuteriumTritium Operation at JET, (special issue) Fusion Eng. Des., 47, (1999).

29. M. Rubel et al., "Fuel Removal from Plasma-Facing Components by Oxidation-Assisted Technique. An Overview of surface morphology after oxidation”, $J$. Nucl. Mater., 363-365, 877 (2007).

30. A. Widdowson et al., "Efficacy of photon cleaning of JET divertor tiles” J. Nucl. Mater., 363-365, 341 (2007).

31. M. Rubel et al., "Thick Co-Deposits and Dust in Controlled Fusion Devices with Carbon Walls: Fuel Inventory and Growth Rate of Co-Deposited Layers”, Phys. Scr., T103, 20 (2003).

32. M. Rubel et al., "Dust Particles in Controlled Fusion Devices”, Nucl. Fusion, 41, 1087 (2001).

33. J. Winter and G. Gebauer, "Dust in Magnetic Confinement Devices and its Impact on Plasma Operation”, J. Nucl. Mater., 266-269, 228 (1999).

34. V. Rohde et al., "Dust Investigations at ASDEX Upgrade”Phys. Scr., T138, 014024 (2009).

35. D. Ivanova et al., "Survey of Dust Formed in the TEXTOR Tokamak: Structure and Fuel Retention”, Phys. Scr., T138, 014025 (2009).

36. G. Counsell and C.H. Wu, "In-situ Detection and Removal of Carbon Debris - a Challenge for the Next Step Fusion Device”, Phys. Scr., T91, 70 (2001).

37. M. Rubel et al., "Overview of Co-deposition and Fuel Inventory in Castellated Divertor Structures at JET”, J. Nucl. Mater., 367-370, 1432 (2007).

38. G. Counsell et al., "Tritium Retention in Next Step Devices and Requirement for Mitigation and Tritium Removal Techniques”, Plasma Phys. Control. Fusion, 48, B189 (2006).

39. R. A. Johnson and A. N. Orlov (Eds), Physics of Radiation Effects in Crystals, Modern Problems in Condensed Matter Sciences, Vol. 13, Noth-Holland, Amsterdam (1986).

40. H. Ullmaier, Contributions to High-Temperature Plasma Physics, K. H. Spatschek and J. Ulenbusch
(Eds), Chap. 3, p. 201, Akademie Verlag, Berlin (1994).

41. H. S. Plendl (Ed.), Nuclear Transmutation Methods and Technologies, North-Holland, Amsterdam 1998. (also : www.chemistrycoach.com/nuclearchem.htm)

42. T. D. Burchell, "Radiation Damage in CarbonCarbon Composites”, Phys. Scr., T64, 17 (1996).

43. Proc. 8th Int. Conf. on Fusion Reactor Materials (ICFRM-8), Sendai, Japan, October, 1997, J. Nucl. Mater., 258-263 (1998), Section 7, pp. 1798-1919.

44. L. Giancarli et al., "Breeding Blanket Modules Testing in ITER: An International Programme on the Way to DEMO”, Fusion Eng. Des., 81, 393 (2006).

45. Y. Poitevin et al., "The Test Blanket Modules Project in Europe”, Fusion Eng. Des., 82, 2164 (2007).

46. A. R. Raffray et al., "Breeding Blanket Concepts for Fusion and Material Requirements", J. Nucl. Mater., 307-311, 21(2002).

47. J. L. Anderson and P. LaMarche, "Tritium Activities in the United States”, Fusion Technol., 28, 479 (1995).

48. D.K. Murdoch et al., "ITER Fuel Cycle Development”, Fusion Sci. Technol., 48, 3 (2005).

49. A. Rolfe, "Remote handling on fusion experiments", Fusion Eng. Des., 36, 91 (1997).

50. A. Möslang et al., "Suitability and Feasibility of the International Fusion Materials Irradiation Facility (IFMIF) for Fusion Materials Studies”, Nucl. Fusion, 40, 619 (2000) 619 (also: www.fzk.de and http://insdell.tokai.jaeri.go.jp/IFMIFHOME/ifmif $h$ ome e.html).

51. Proc. Int. Conf. on Fusion Reactor Materials (ICFRM), J. Nucl. Mater., 133-134 (1985), 141-143 (1986), 155-157 (1988), 179-181 (1991), 212-215 (1994), 258-263 (1998), 283-287 (2000), 307-311 (2002), 329-333 (2004), 367-370 (2007), 386-399 (2009).

52. Proc. $15^{\text {th }}$ Int. Conference on Fusion Reactor Materials (ICFRM-15), Fusion Sci. Technol., 62, (2012). 